\title{
Species delimitation in the East Asian species of the relict tree genus Zelkova (Ulmaceae): A complex history of diversification and admixture among species
}

\author{
Yamama Naciri $^{\mathrm{a}, \mathrm{b}, *}$, Camille Christe ${ }^{\mathrm{a}}$, Sébastien Bétrisey ${ }^{\mathrm{c}, \mathrm{d}}$, Yi-Gang Song ${ }^{\mathrm{d}, \mathrm{e}}$, Min Deng ${ }^{\mathrm{e}}$, \\ Giuseppe Garfi ${ }^{\mathrm{f}}$, Gregor Kozlowski ${ }^{\mathrm{c}, \mathrm{d}}$ \\ ${ }^{a}$ Conservatoire et Jardin botaniques de la Ville de Genève, Chemin de l'Impératrice 1, 1292 Chambésy, Genève, Switzerland \\ ${ }^{\mathrm{b}}$ Laboratoire de Systématique végétale et Biodiversité, University of Geneva, Chemin de l'Impératrice 1, 1292 Chambésy, Genève, Switzerland \\ ${ }^{\mathrm{c}}$ Natural History Museum Fribourg, Chemin du Musée 6, 1700 Fribourg, Switzerland \\ d Department of Biology and Botanic Garden, University of Fribourg, Chemin du Musée 10, 1700 Fribourg, Switzerland \\ e Shanghai Chenshan Plant Science Research Center, Chinese Academy of Sciences, 201602 Shanghai, China \\ ${ }_{\mathrm{f}}^{\mathrm{f}}$ Institute of Biosciences and BioResources, National Research Council, Corso Calatafimi 414, 90129 Palermo, Italy
}

A R T I C L E IN F O

Keywords:

Admixture

Bayesian analyses

Chloroplast markers

Microsatellites

Phylogeography

Sino-Japanese Floristic Region

\begin{abstract}
A B S T R A C T
Zelkova species, trees of the elm family (Ulmaceae), are part of the Cenozoic relict flora. In western Eurasia, the genus comprises three species that are restricted to disjunct areas (Z. sicula on Sicily, Z. abelicea on Crete and Z. carpinifolia in Transcaucasia). The situation is different in East Asia, where three species (Z. serrata, Z. schneideriana and $Z$. sinica) have at least partly overlapping distributions. The phylogenetic and phylogeographic status of these East Asian species is still not well understood, mainly since all previous studies used almost exclusively plant material collected in botanical gardens and were based on very small numbers of individuals. Our study is the first based on 33 natural populations covering all important areas with Zelkova species in the Sino-Japanese Floristic Region. Chloroplast and microsatellite markers were used, and Bayesian analyses were run for both types of markers. East Asian Zelkova species cluster into two groups that partially overlap when comparing the two types of markers. For chloroplast markers, the two groups coincide with all Japanese, some Korean and northern Chinese Z. serrata in one group and all other individuals in the other group, regardless of whether they are attributed to Z. serrata, Z. sinica or Z. schneideriana from Korea, mainland China and Taiwan. At the nuclear level, however, the clustering clearly groups all the $Z$. serrata individuals together, regardless of whether they are from Japan, Korea or China, and the two other species in a second group. This complex genetic pattern in East Asian Zelkova species is most likely due to a combination of ancient diversification and speciation events and more recent hybridization during the last glacial/interglacial retractions and recolonizations. One of the surprising results of our study concerns the populations from Taiwan, which are genetically similar to Z. schneideriana. Thus, their assignation to a separate taxon (Z. tarokoensis) or to a variety of Z. serrata (Z. serrata var. tarokoensis), as currently reported in all local and national floras, might be in need of revision. Furthermore, our results indicate that the East Asian species are more closely related to Z. carpinifolia than to any other Western European species. Haplotypes of Z. sicula and Z. abelicea (Mediterranean region) as well as those of $Z$. sinica and $Z$. schneideriana (East Asia) seem to have diversified more recently. The most ancient haplotypes are found among the western Eurasian Z. carpinifolia and the East Asian Z. serrata. This result is in agreement with the carpinifolia and serrata-like morphotypes commonly found in the fossil record.
\end{abstract}

\section{Introduction}

Demographic regimes have profound effects on species genetic diversity and structuration (Arenas et al., 2012). The amount of genetic variation that accumulates during a species' life span depends on its long-term effective population size. This effective size is in turn impacted by demographic events such as expansions or bottlenecks (Excoffier, 2004). It has been shown, for instance, that demographic and spatial expansions leave specific footprints in DNA that can be traced back (Excoffier et al., 2009). Spatial expansions can be

\footnotetext{
* Corresponding author at: Conservatoire et Jardin botaniques de la Ville de Genève, Chemin de l'Impératrice 1, 1292 Chambésy, Genève, Switzerland.

E-mail address: yamama.naciri@ville-ge.ch (Y. Naciri).
} 
associated with gene surfing (Klopfstein et al., 2006), which can lead to large geographic areas being covered with unique alleles or haplotypes. In contrast, demographic expansions are characterized by an excess of rare mutations and star-like networks of genes (Posada and Crandall, 2001). Arenas et al. (2012) showed that cycles of expansions and retractions, such as those observed during Quaternary glaciations, lead to specific footprints in gene networks and molecular diversities. It is commonly found that species within a genus have experienced different demographic events, therefore showing very different genetic diversities (Christe et al., 2014a). It is therefore interesting to study genera comprising species that have similar life history traits (outcrossing trees) but that inhabit distant parts of the world in which the Quaternary glaciations had differing impacts on plants due to the presence or absence of strong geographic barriers. This is specifically the case with the relict tree genus Zelkova of the elm family (Ulmaceae).

Zelkova species are part of the Cenozoic relict flora along with other tree or shrub genera such as Albizia, Diospyros, Gleditsia, Hamamelis, Juglans, Liquidambar, Parrotia and Pterocarya (Milne and Abbott, 2002; Médail and Quézel, 2003; Denk et al., 2001; Kozlowski and Gratzfeld, 2013; Kozlowski et al., 2018). In western Eurasia, the genus comprises three species that are restricted to disjunct areas: $Z$. sicula is a narrow endemic of Sicily, only known from two populations, one of which was discovered at the very beginning of the twenty-first century (Garfi et al., 2011); Z. abelicea is endemic to Crete and grows in each of the four mountainous regions of the island (Levka Ori, Psiloritis, Dikti and Thripti; Kozlowski et al., 2014); and Z. carpinifolia ranges from eastern Turkey and Georgia (Transcaucasia) to Iran (Kvavadze and Connor, 2005). The three western Eurasian species display different chloroplast haplotypes organized into three clusters separated by many mutations, which indicates a long history of isolation, predating the Quaternary oscillations. It has been assumed, for instance, that Z. abelicea has existed in Crete for several million years and has diversified on site (Zidianakis et al., 2010; Christe et al., 2014b).

Within the western Eurasian species, with the exception of $Z$. sicula, important chloroplast diversity has been found, which is highly structured according to geography. These features allowed us to validate the species identity of trees grown in botanical gardens and to further identify the geographic origin of $Z$. carpinifolia and Z. abelicea trees found in living collections with high confidence (Christe et al., 2014c).

The situation is rather different for Zelkova in East Asia, where three species are also found but their respective distributions are, at least partly, overlapping (Kozlowski and Gratzfeld, 2013; Kozlowski et al., 2018). Zelkova serrata occurs naturally in Japan, the Korean Peninsula and in some regions of China. This species favors a mild climate, growing particularly well in limestone valleys on rich, moist soils, although it can also thrive in drier environments and under poorer soil conditions. Occurring from lowland to mountain forests (mainly between 500 and $2000 \mathrm{~m}$ a.s.1.), Z. serrata is usually found in riparian habitats, in ravines and on shady slopes (Kozlowski and Gratzfeld, 2013; Kozlowski et al., 2018). Zelkova sinica and Z. schneideriana are endemic to China and grow in the vicinity of small rivers at a wide range of altitudes (200-2800 m a.s.l.; Fang et al., 2011). A fourth East Asian taxon, Z. tarokoensis, was described in Taiwan (Hayata, 1920), but its species status is still debated. Most authors have suggested that Z. tarokoensis is a subspecies or a local variety of Z. serrata (Li, 1952). The East-Asian Zelkova species are large trees (30-35 m tall), either appreciated for their high-quality timber (e.g., Z. schneideriana) or used in traditional herbal medicine (bark and leaves of $Z$. serrata). In Japan, Z. serrata is often planted in monasteries and considered a sacred tree (Kozlowski and Gratzfeld, 2013: Kozlowski et al., 2018). In China, Zelkova species are overexploited in many regions (Zheng-yi and Raven, 2003) and/or threatened by habitat fragmentation (Fang et al., 2007). Due to overlapping distributions, hybridization events among the East Asian Zelkova species cannot be excluded. The difficulties we faced in confidently identifying some trees presenting intermediate morphological features might be a sign of such hybridization events. Overall, the
East Asian species are poorly studied (but see Fukatsu et al., 2012; Zhang et al., 2017), and the Flora of China only gives morphological descriptions (Zheng-yi and Raven, 2003), with scarce information about their ecology and biology.

The Sino-Japanese Floristic Region (SJFR), where the East Asian Zelkova species occur, and especially subtropical China, is a global center of vascular plant diversity (Ricklefs and Qian, 2000; Barthlott, 2005) and was the most important glacial refugium for relict trees (Milne and Abbott, 2002; Milne, 2006; Qiu et al., 2011). This vast region has a complex topography and was less influenced by the Quaternary glacial-interglacial cycles than were Europe and North America, and it was never covered by ice sheets (Qiu et al., 2011; Wan et al., 2017). Recently, a number of phylogeographic investigations carried out in this region have shown strong genetic structure in various woody species (Tian et al., 2010; Zhang et al., 2013; Shi et al., 2014; Sun et al., 2014; Xu et al., 2015; Tian et al., 2015; Wan et al., 2017). However, many of the previous studies in this area focused on single species, without any comparisons with related species inhabiting other refugial areas of the world (Qiu et al., 2011). One of the exceptions is the study of Zhang et al. (2017).

To help fill this gap in knowledge, we have investigated the phylogeography of all three East Asian species of Zelkova in comparison with that of their western Eurasian counterparts, using the same two chloroplast markers analyzed in Christe et al. (2014b). We further address the issue of species delimitations among East Asian Zelkova species using six nuclear microsatellite markers and Bayesian analyses. The genus Zelkova is an ideal model to examine the effects of drift and recolonization processes in two areas with different geographic features: Europe and Transcaucasia, where the effect of Quaternary glaciations on plant distributions was strongly shaped by, among other factors, the presence of many east-west barriers (e.g., the Alps, the Pyrenees and the Mediterranean Sea), and East Asia (the SJFR), where the absence of strong barriers south and east of the Himalayas and less severe glaciations allowed for fast south-to-north recolonization processes as well as higher opportunities for secondary contact among species during interglacial periods. Our hypothesis is therefore that the East Asian species of Zelkova are admixed, at least to a certain degree, and that their species boundaries are more difficult to determine than those of their western Eurasian counterparts.

\section{Material and methods}

\subsection{Sampling}

Leaves were collected from a total of 324 individuals from 33 populations in Japan, South Korea, China and Taiwan and dried in silica gel (Table 1, Fig. 1); these samples covered all important areas with Zelkova species in the SJFR. Population sizes ranged between 1 and 23 . Zelkova serrata was the most intensively sampled species (167 individuals from 16 populations), followed by Z. sinica (93 individuals from 9 populations) and $Z$. schneideriana (64 individuals from 8 populations).

\subsection{Molecular analyses}

DNA was extracted from dried leaves using a Macherey-Nagel NucleoSpin(C) Plant II kit (Düren, Germany) following the supplier's instructions. Two $50 \mu$ l elutions were obtained for each sample. The two chloroplast markers, namely, trnH-psbA (Shaw et al., 2005) and trnL (Taberlet et al., 1991), were amplified as in Christe et al. (2014b), and for each locus, both strands were sequenced on a Beckman-Coulter GEXP automated sequencer (Brea, CA, USA) following the manufacturer's protocol. For the chloroplast markers, all populations were analyzed, with a maximum number of 15 individuals per population. Microsatellite primers were retrieved from Fukatsu et al. (2005). Since these microsatellites were designed for $Z$. serrata, it was expected that 


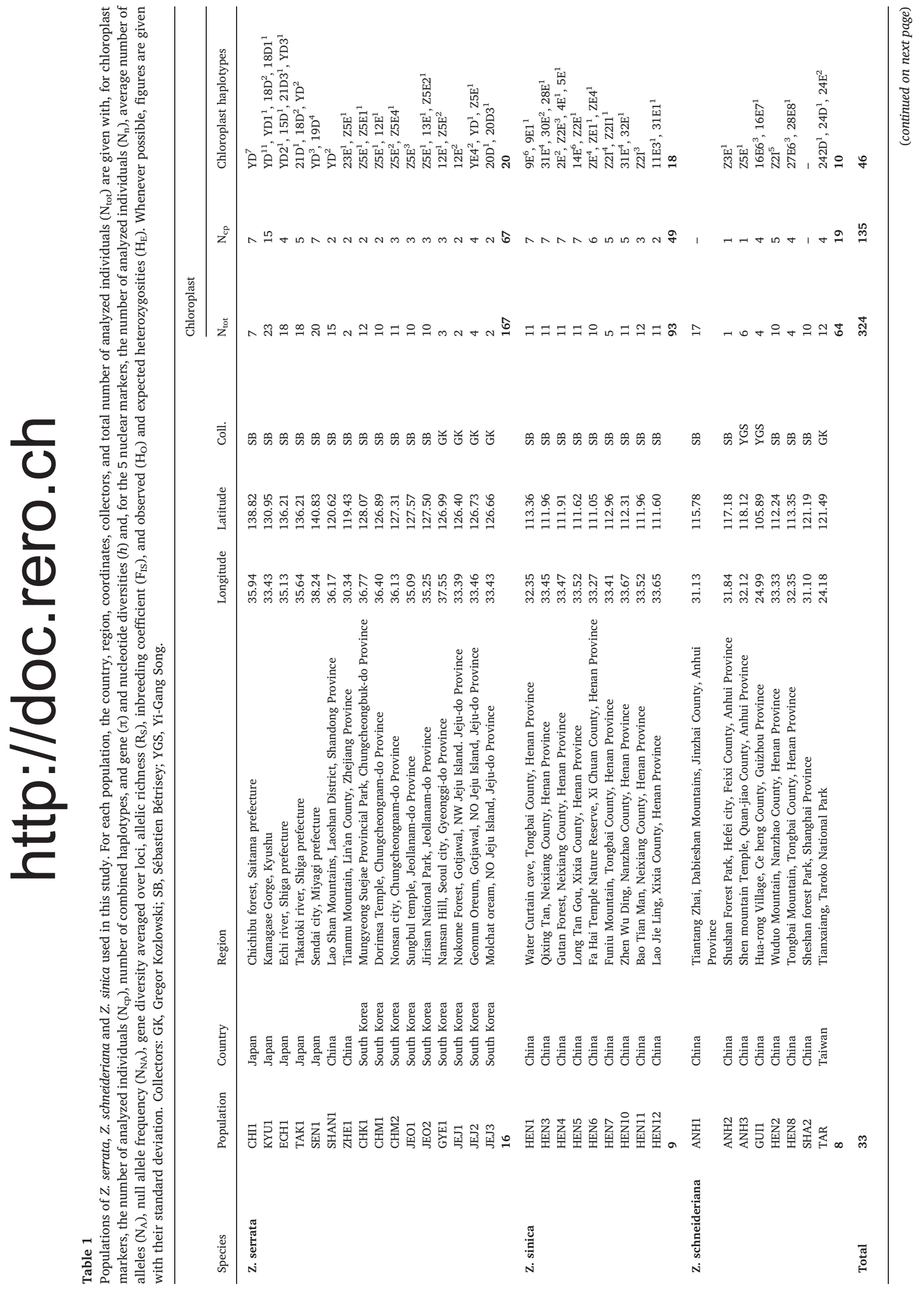




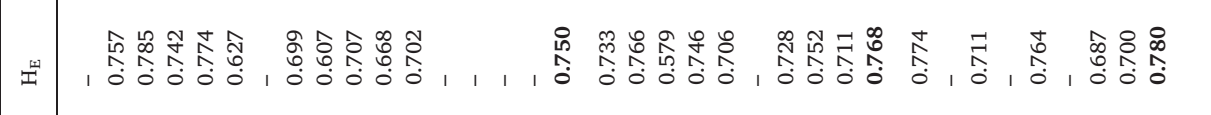

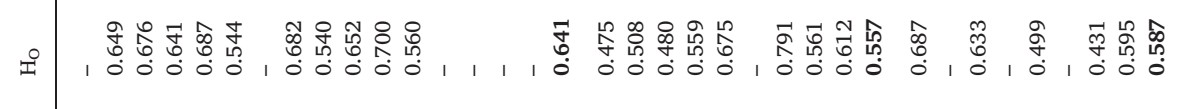

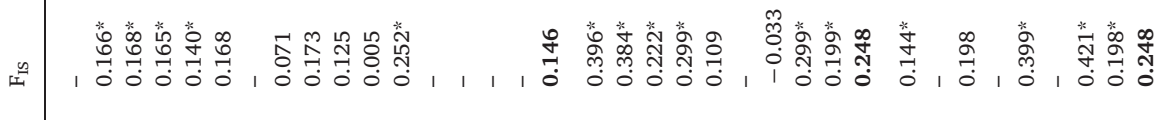

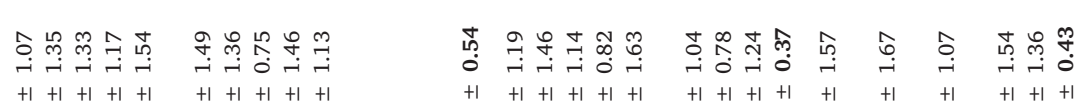

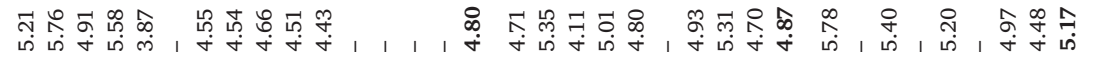

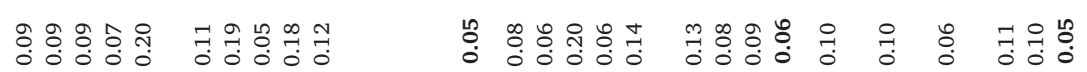

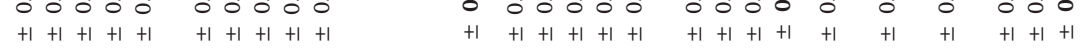

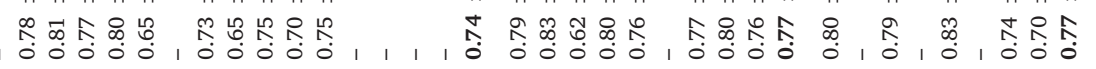

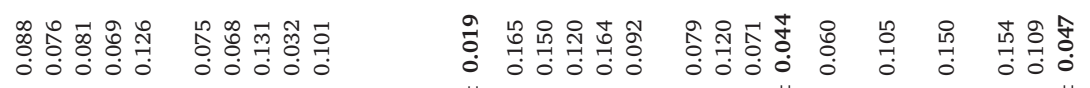

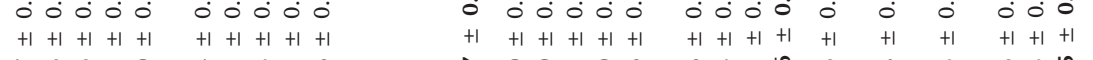

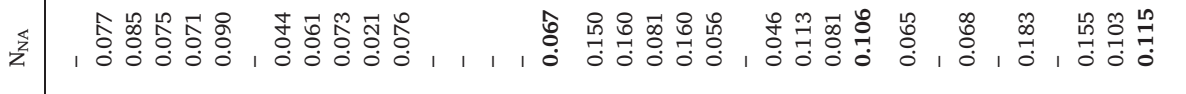

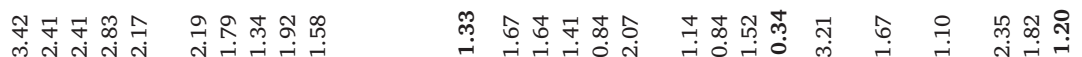

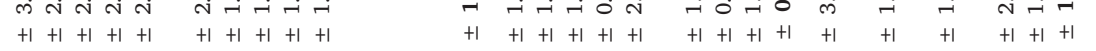

z

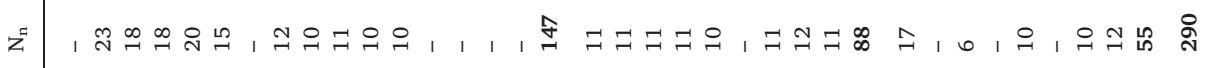

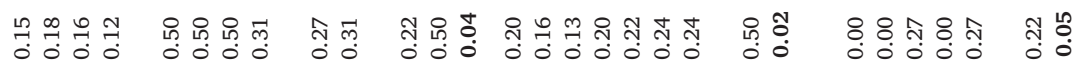

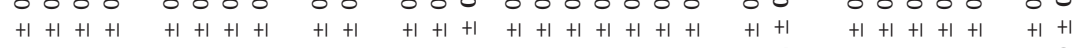

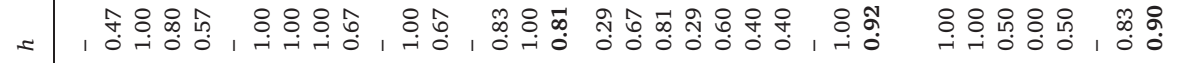

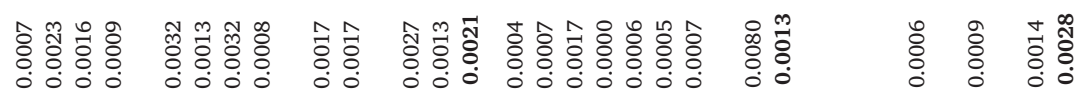

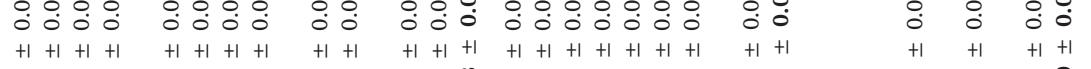

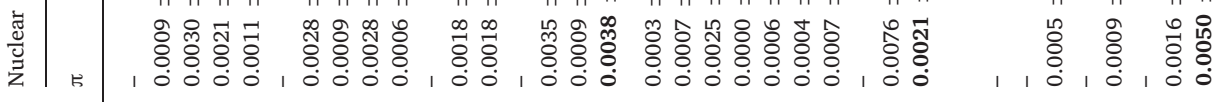


not all of them would work on related species. The fourteen loci were first amplified using regular primers from four individuals of each of $Z$. serrata, Z. schneideriana and Z. sinica using the recommended PCR conditions and visualized on a $1 \%$ agarose gel. Only six of the loci were regularly amplified for the three species after PCR condition adjustments and were subsequently used: bczs103b, bczs144a, bczs157c, bczs184a, bczs186a and bczs431a. For genotyping, fluorescent reverse primers were used, and loci were multiplexed into two sets of three markers. Multiplexes were run on a Beckman-Coulter GEXP automated sequencer following the manufacturer's protocol. Alleles were named according to their size and recorded manually. The six loci were analyzed for a total of 290 individuals, and $29 \%$ of the individuals were genotyped at least twice to check for allele-calling repeatability. Since the microsatellites were expected to be highly polymorphic, only populations with 10 or more individuals were analyzed to obtain accurate allele frequency estimates.

\subsection{Sequence analyses}

Sequences were assembled using Sequencher version 4.8 and then manually aligned in BioEdit version 7.1.9 (Hall, 1999). The chloroplast is generally considered a single locus, and complete linkage disequilibrium is usually assumed among loci. However, we checked for linkage disequilibrium among the two chloroplast loci by means of 10,000 iterations before combining them as chloroplast haplotypes, since this test allows for the identification of paralogous sequences that might have been erroneously amplified, something that is usually overlooked in plants (Arthofer et al., 2010; Naciri and Manen, 2010). Chloroplast haplotypes were retrieved from the alignment, and their frequencies were calculated for Network analyses (see below). Prior to analysis, a highly polymorphic polyA region was removed at the end of the alignment, and indels and inversions, commonly found in trnH-psbA but also found in trnL (Whitlock et al., 2010), were manually coded as 0 and 1 , such that they could be considered as single mutation steps in Network analyses. For BEAST analyses, indels and inversions were coded following Simmons and Ochoterena (2000) by changing bases in the alignment such that substitutions were imposed for them. The impact of coding was checked using model selection in PAUP, and no difference in substitution models was found before and after indel coding for each locus. Indel and inversion events were taken into account in all analyses, as they have been shown to provide relevant phylogeographical information (Ingvarsson et al., 2003; Rendell and Ennos, 2003; Christe et al., 2014a). Sequences were deposited into GenBank under accessions n MK249385 - MK249652.

Haplotype $(h)$ and nucleotide $(\pi)$ diversities were estimated for $Z$. sinica, Z. serrata and Z. schneideriana (Nei, 1987). Analyses of molecular variance (AMOVAs; Excoffier et al., 1992) were run to assess the amount of genetic variance found among populations $\left(\mathrm{F}_{\mathrm{ST}}\right)$ and among species $\left(\mathrm{F}_{\mathrm{CT}}\right)$, using pairwise differences as the genetic distance among haplotypes. Scenarios of past demographic or spatial expansions were tested for the three species. All the former analyses were conducted using ARLEQUIN version 3.1.5.2 (Excoffier et al., 2007), and 10,000 permutations were performed when significance tests were needed. Tajima's D and Fu's Fs tests of neutrality were computed in ARLEQUIN to detect selection or demographic effects. As recommended by Excoffier et al. (2007), who noted the special behavior of the Fs statistic, Fu's Fs was considered significant only when $\mathrm{P}<0.02$ (and not when $\mathrm{P}<0.05)$.

Median-joining networks (MJNs) were drawn for the combined chloroplast haplotypes using the software Network (Bandelt et al., 1999), which is provided freely on the website fluxus-engineering.com. First, all kinds of mutations, whether they were site mutations, indels or inversions, were equally weighted and treated as single-step events. In a second step, the mutations that appeared several times in the network were inversely weighted by their frequency, and a second network was drawn following Bandelt et al. (1999), who suggested this procedure to take homoplasy into account. The geographical distribution of chloroplast haplotypes was visualized on maps using ArcMap GIS (Environmental Systems Research Institute).

A species tree was inferred using the software STACEY (Jones et al., 2015; Jones, 2017), embedded in BEAST version 2.3.1. STACEY implements the multi-species coalescent model defined by Yang and Rannala (2010) to reconstruct a species tree that takes incomplete lineage sorting into account. The model also deals with uncertainties in species identification, with each population/individual here being considered as a potential cluster or species. This option was chosen to test for species delimitation among the Asian lineages, which was our primary goal, and we therefore used all individuals sequenced for both loci. However, the option does not allow for dating using fossil records. The priors were set as follows in STACEY: we used the most appropriate substitution models found in PAUP according to the AICc, i.e., HKY + I and JC $\mathrm{s}$ for $t r n \mathrm{~L}$ and $t r n \mathrm{H}-p s b \mathrm{~A}$, respectively; a strict and a relaxed lognormal molecular clock for trnL and trnH-psbA, respectively; and a mean rate of 1 for trnH-psbA. The model choice for substitutions and clock rates was performed in PAUP and BEAST, respectively. For trnHpsbA, lognormal rates were imposed with a lognormal prior for the mean (mean: 0.0, SD: 1.0) and a gamma prior for the standard deviation (alpha: 0.5396, beta: 0.3819), whereas for trnL, a uniform prior was imposed for the rates. We used lognormal (mean: 1.0, SD: 1.25) priors for the transition/transversion ratios for trnL. The collapse height and collapse weight were set to $10^{-4}$ and 0.5 , respectively (Jones, 2017). We used lognormal priors for the species tree growth rate (bdcGrowthRate.t:Species; mean: 3.0, SD: 2.0) and for the population scale (popPriorScale; mean: -4.0 , SD: 1 ), and beta priors (alpha: 1.0, beta: 1.0) for the relative death rate (relDeathRate.t:Species) and the collapse weight (collapseWeight.t:Species). Three independent runs were obtained with 800-900 million generations that gave ESS values higher than 200 for all the parameters except the likelihood, which ranged between 50 and 259 depending on the run. The three runs, however, converged toward very similar values for all other parameters. The three runs were then combined using LogCombiner version 2.3.2 to obtain a new log file in which all parameters had ESS values higher than 200 (ESS $=165$ for the likelihood). The final species tree was obtained using the same software by sampling a tree every 3.6 million generations, with a $10 \%$ burn-in for each run. The tree was subsequently annotated using TreeAnnotator version 2.3.2 and visualized using FigTree version 1.4.3. Posterior probabilities (PPs) higher than 0.5 were given as branch labels. The speciesDA tool, provided in STACEY, was used to compute the posterior probabilities that pairs of populations belonged to the same multispecies coalescent cluster (MSCC; Jones, 2017), using a collapse height of 0.005 . An R script, also provided in STACEY modified by Simon Crameri and available on github.com/ scrameri, was finally used to compute a two-dimensional pairwise matrix, where the cells were colored according to the posterior probabilities that pairs of populations belonged to the same MSCC.

Since the species tree was ultrametric, it was used to infer approximate dates for clade diversifications. It was assumed that the stem age of Zelkova was at least 55 million years. Date estimates were then obtained by comparing the levels of substitutions per site relative to the stem.

\subsection{Microsatellite analyses}

FSTAT version 2.9.3.2 was used to compute standard indices within populations, such as the gene diversity $(\mathrm{He})$, the allelic richness $(\mathrm{Rs})$, and the inbreeding coefficient (Fis). Pairwise $\mathrm{F}_{\mathrm{ST}}$ values were computed and tested for significance using 10,000 permutations. A false discovery rate correction was applied for multiple tests (Benjamini and Yekutieli, 2001). A heatmap with an associated UPGMA dendrogram was built for pairwise $\mathrm{F}_{\mathrm{ST}}$ values in the $\mathrm{R}$ package heatmap. 2 with the function hclust. The null allele frequency was calculated with the $\mathrm{R}$ package Genepop (Rousset, 2008). STRUCTURE version 2.3.4 (Pritchard et al., 

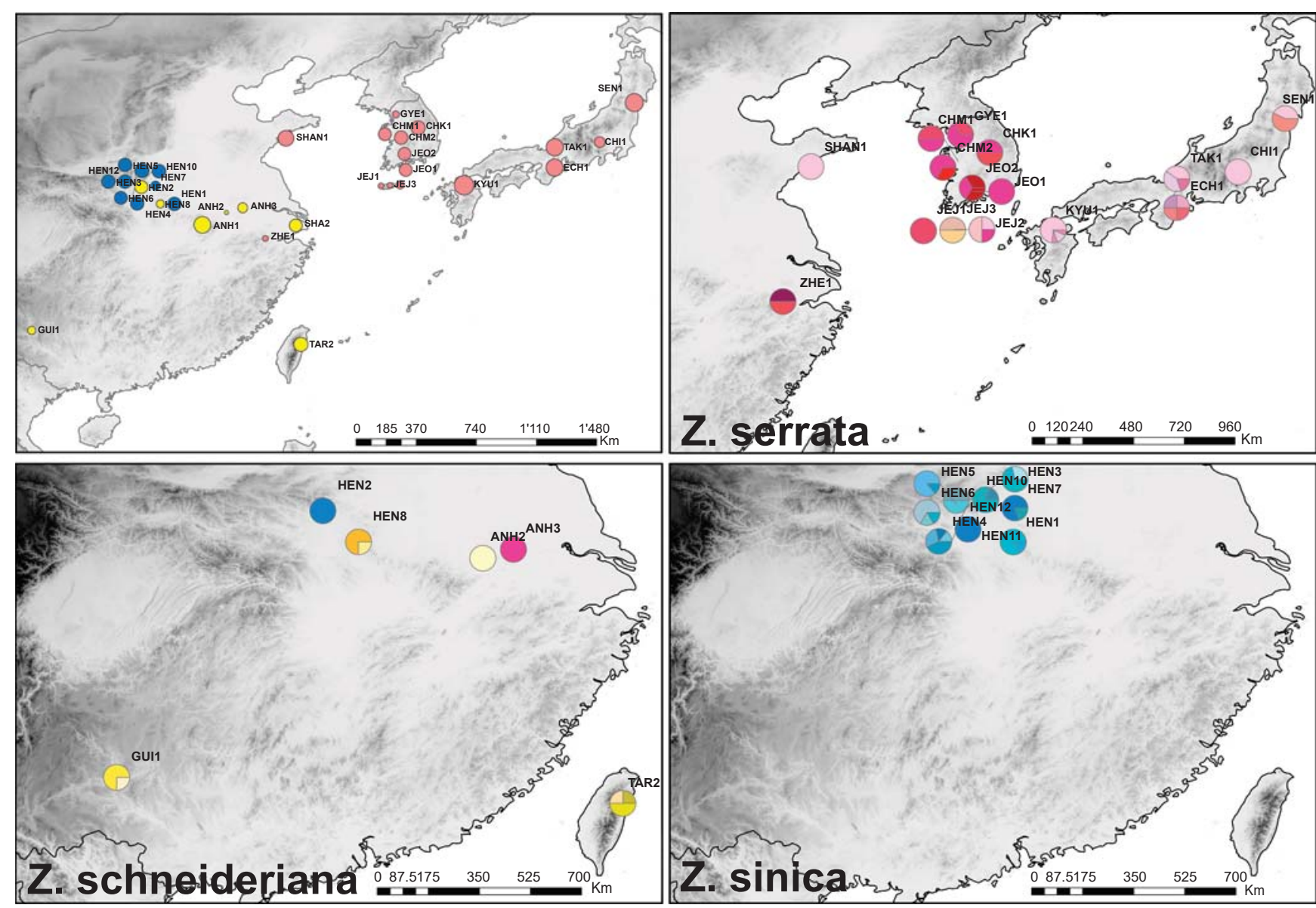

Fig. 1. (a) Geographical distribution of sampled East Asian Zelkova: Z. serrata (red), Z. schneideriana (yellow) and Z. sinica (blue). The size of each circle is proportional to the total number of individuals sampled for each population. (b) Geographical distribution of $Z$. serrata haplotypes, (c) Geographical distribution of $Z$. schneideriana haplotypes, (d) Geographical distribution of $Z$. sinica haplotypes. Not all populations were sequenced (SHA2 and HA1). (For interpretation of the references to colour in this figure legend, the reader is referred to the web version of this article.)

2000) was used to infer the most likely number of groups for the whole set of populations, using a Bayesian approach. The parameters used were as follows: each run was performed with 100,000 burn-in iterations and 100,000 subsequent Monte Carlo Markov chain (MCMC) runs, with $\mathrm{K}$ values ranging from 2 to 10 and repeated 20 times for each value of $\mathrm{K}$. The more likely value of $\mathrm{K}$ was assessed using Evanno's $\Delta \mathrm{K}$ method (Evanno et al., 2005). Further analyses were then conducted within each of the newly delineated groups, using $\mathrm{K}$ values ranging from 2 to 10 and the same parameters as before.

Bottleneck software (Cornuet and Luikart, 1996) was used to test for potential dramatic reductions in effective population size within each STRUCTURE group separately, since working on individual populations was not feasible due to low sample sizes for most of them. All possible mutation models were assayed: the infinite allele model (IAM), the stepwise mutation model (SSM) and the two-phase model (TPM), the latter two of which are usually assumed to be more suitable for microsatellites (Di Rienzo et al., 1994).

\section{Results}

\subsection{High chloroplast diversity}

From a 1514 bp alignment that also included all haplotypes found for Z. abelicea, Z. carpinifolia and Z. sicula (Christe et al., 2014b), 46 new combined haplotypes were detected for the two cpDNA loci in the 135 individuals analyzed for the three Asian species (Table 1). Most haplotypes were restricted to a single species, but two of them were shared among taxa: Z5E (Z. serrata and Z. schneideriana) and Z2I (Z. sinica and
$Z$. schneideriana). The highest diversity was found within $Z$. serrata, with 20 haplotypes, followed by Z. sinica (18 haplotypes) and Z. schneideriana (10 haplotypes). The highest gene diversity was found in $Z$. sinica and $Z$. schneideriana $(h=0.92 \pm 0.02$ and $0.90 \pm 0.05$, respectively), and the lowest, in $Z$. serrata $(h=0.81 \pm 0.04$; Table 1$)$. $Z$. schneideriana had the highest nucleotide diversity $(\pi=0.0050 \pm$ $0.0028)$, followed by $Z$. serrata $(\pi=0.0038 \pm 0.0021)$ and $Z$. sinica $(\pi=0.0021 \pm 0.0013)$.

Of the 31 populations of $Z$. serrata, Z. sinica and Z. schneideriana, 23 were polymorphic, with 12 of 16 in $Z$. serrata (71\%), 8 of 9 in $Z$. sinica (89\%) and 3 of 6 in Z. schneideriana (50\%).

Both neutrality tests were non significant for $Z$. schneideriana (Fs $=-0.74, \quad P=0.37 ; \quad D=0.07, \quad P=0.57$ ) and for $Z$. serrata ( $F s=-5.28, P=0.04 ; D=-0.46, P=0.37$ ), whereas both tests were significant for $Z$. sinica ( $F s=-10.24, P=0.00 ; D=-1.59, P=0.04$ ), pointing to an excess of rare mutations within the third species.

When the Asian species were analyzed together, $32.5 \%$ of the chloroplast genetic variation was attributed to differences among species, and $50.7 \%$, to differences among populations within species. When the species were analyzed separately, the highest genetic differentiation was found for $Z$. schneideriana $\left(\mathrm{F}_{\mathrm{ST}}=0.91\right)$, followed by $Z$. serrata $\left(\mathrm{F}_{\mathrm{ST}}=0.69\right)$ and $Z$. sinica $\left(\mathrm{F}_{\mathrm{ST}}=0.65\right)$.

\subsection{Two groups at the chloroplast level}

The haplotype median-joining network (MJN) clearly separated the three East Asian species from the three western Eurasian species. The MJN further split the East Asian haplotypes into two main groups. The 


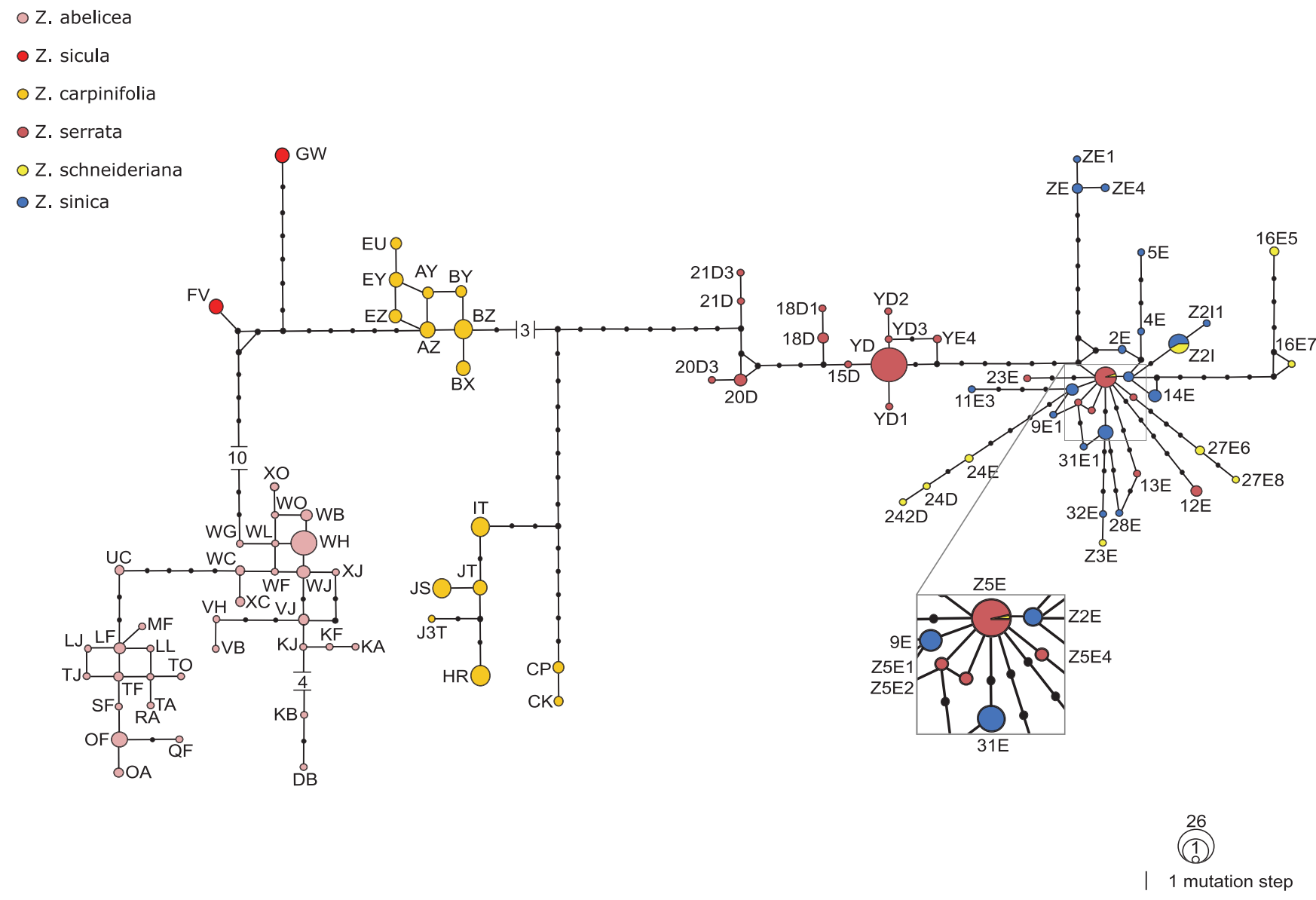

Fig. 2. Haplotype network based on the two combined chloroplast markers (trnH-psbA and trnL). Missing haplotypes are represented as black dots, the size of each haplotype is proportional to the number of individuals that share it, and the color of each haplotype corresponds to the species that it belongs to ( $Z$. serrata: red, $Z$. schneideriana: yellow, Z. sinica: blue). (For interpretation of the references to colour in this figure legend, the reader is referred to the web version of this article.)

first group was reticulate and comprised 12 haplotypes confined to $Z$. serrata; the second group, with a star-like shape, comprised haplotypes belonging to all three species (Fig. 2). Haplotypes belonging to one or the other species were scattered in the star-like part of the network, with those of $Z$. serrata occupying the network center (i.e., underived) and $Z$. sinica haplotypes directly connected to this center (slightly derived). The haplotypes of $Z$. schneideriana were found at the periphery of the network (more derived). Haplotypes of the reticulate group belonged to individuals collected in Japan, the Lao Shan Mountains and 2 populations from Jeju Island in South Korea (Fig. 1). Haplotypes belonging to the star-like group were found exclusively in South Korea and China. None of the demographic or spatial scenarios of expansion could be rejected when the two clusters were tested separately $(P>0.05)$.

The species tree confirmed that the East Asian species were divided into two moderately supported groups (Fig. 3a). The first group $(\mathrm{PP}=0.78)$ contained all populations of $Z$. serrata from Japan (SEN1, CHI1, TAK1, ECH1, and KYU1) in addition to SHAN1 (China) and JEJ3 (South Korea). The second group ( $\mathrm{PP}=0.89$ ) contained all other populations. Within this cluster, only two groups were well supported, both within Z. sinica: HEN2, HEN6 and HEN11 (PP = 0.97) and HEN3, HEN10 and HEN12 ( $\mathrm{PP}=0.93$ ). Accordingly, the similarity matrix showed two groups, with some genetic structure within the largest one (Fig. 3b). For the western Eurasian species, a striking geographic pattern was observed. The two haplotype lineages within $Z$. carpinifolia diverged before the split between $Z$. abelicea and $Z$. sicula, and the latter two species were sister to the western lineage of $Z$. carpinifolia. The two lineages of $Z$. carpinifolia were strongly supported, but their relationship was not clear $(\mathrm{PP}=0.65)$. The first clade $(\mathrm{PP}=1)$, sister to $Z$. sicula and $Z$. abelicea
$(\mathrm{PP}=0.91)$, comprised populations from Turkey and Georgia, except the two easternmost Georgian populations (TBI and BAB), whereas the second clade ( $\mathrm{PP}=0.98)$ included all populations from Azerbaijan, Iran and eastern Georgia. Within Z. carpinifolia, only the clade comprising the three westernmost populations bordering the Black Sea (TRA, MAR and IAN, $\mathrm{PP}=0.93)$ and that containing PAR and TA2 $(\mathrm{PP}=1)$ at the Azerbaijan-Iranian border were found to be well supported. Accordingly, the similarity matrix showed that $Z$. carpinifolia was divided into 6 MSCC clusters (Fig. 3b). Z. sicula was sister to Z. abelicea ( $\mathrm{PP}=0.99$ ), and all populations of $Z$. abelicea formed a highly supported clade $(\mathrm{PP}=1)$. According to the similarity matrix, Z. sicula was divided into two MSCCs corresponding to the two existing populations, whereas all populations of Z. abelicea fell within a single MSCC (Fig. 3b).

\subsection{Nuclear differentiation patterns: two different groups}

The first analysis was conducted with all six microsatellites. One locus (bczs431a) was discarded from further analyses because selection was suspected due to a very low number of alleles ( 5 versus 12 to 23 for the other loci) associated with a high $\mathrm{F}_{\mathrm{ST}}$ value ( 0.427 versus 0.069-0.163 for all other microsatellites). The number of alleles found for the five remaining microsatellites ranged between 12 (bczs157c) and 23 (bczs144a), with a mean of 17.6 over the 5 loci. The overall allelic richness (based on 6 diploid individuals) ranged from 1.969 (bczs157c) to 8.000 (bczs144a). $F_{I S}$ values were found to be significantly positive at the nominal level of $5 \%$ for 14 of the 23 populations. The $F_{I S}$ was, on average, lower in $Z$. serrata ( 0.146 ; with significant values ranging from 0.140 to 0.252 ) and higher in $Z$. sinica (0.248; significant values ranging from 0.199 to 0.396 ) and $Z$. 
schneideriana (0.248; significant values ranging from 0.144 to 0.421 ; Table 1). Pairwise $\mathrm{F}_{\mathrm{ST}}$ values between all pairs of populations revealed two groups within the three species studied (Fig. 4), a result also found in the STRUCTURE analyses (below). All populations of $Z$. serrata clustered together and were well differentiated from $Z$. sinica and $Z$. schneideriana.

Within Z. serrata, populations were weakly differentiated (Fig. 4). The dendrogram displayed on top shows that the only Chinese population sampled for microsatellites (SHAN1) in our dataset was the most differentiated population within Z. serrata. Populations from Korea and Japan clustered together. Within Z. schneideriana and Z. sinica, one population of $Z$. sinica (HEN4) did not cluster with the two latter species.

STRUCTURE analyses showed that $\Delta \mathrm{K}$ was maximized for two groups, one corresponding to $Z$. serrata and the second including $Z$. schneideriana and Z. sinica (Fig. 5a). Within the first group, Z. serrata was homogeneous across its range, and this was confirmed by the low values of $\mathrm{F}_{\mathrm{ST}}$ found within the species $(0.056$ versus 0.071 for $Z$. sinica and 0.077 for $Z$. schneideriana). Within the second group, $Z$. sinica (blue) was more structured, with two groups (Fig. 5b), and the two potential sister species, namely, $Z$. sinica and $Z$. schneideriana (yellow), were generally recognizable. However, these two species seemed to be admixed (Figs. 2 and $5 b$ ), with two populations attributed to Z. schneideriana (ANH1 and HEN2) showing a balanced hybrid index (ANH1: h_index_yellow $=0.581$, $h \_$in -

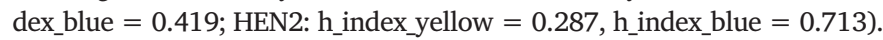

Given the STRUCTURE results, Bottleneck software was run on $Z$. serrata and on $Z$. sinica plus $Z$. schneideriana. No significant excess of heterozygotes was found using a sign test, but the Wilcoxon test, assuming the infinite allele model (IAM), revealed significant heterozygote excesses for $Z$. serrata $(\mathrm{P}=0.047)$ and for $Z$. sinica and $Z$. schneideriana $(\mathrm{P}=0.016)$. The same test, however, gave no significant results when other mutation models were assumed, such as the stepwise mutation model (SSM) or the two-phase model (TPM).

\section{Discussion}

Modern patterns of endemism and disjunction of relict trees such as Zelkova are shaped by past changes in climate, tectonics, and sea level that influenced their range dynamics and species divergence (Qiu et al., 2011). The warm temperate climate regions of East Asia are considered to be one of the most important areas for the long-term persistence of relict forest flora (Milne, 2006, Lu et al., 2018). Accordingly, the members of the genus Zelkova in East Asia, as many other so-called Arcto-Tertiary relict species, have persisted for millions of years with little morphological change (Kozlowski and Gratzfeld, 2013). However, such morphological stasis does not always correlate with genetic diversification (Cao et al., 2016).

\subsection{Species boundaries and partial discordance between chloroplast and nuclear markers}

Using chloroplast and microsatellite markers, we found that the East-Asian Zelkova species clustered into two groups that partially overlapped. For the chloroplast markers, the first lineage coincides with all Japanese, some Korean and North Chinese $Z$. serrata. The second

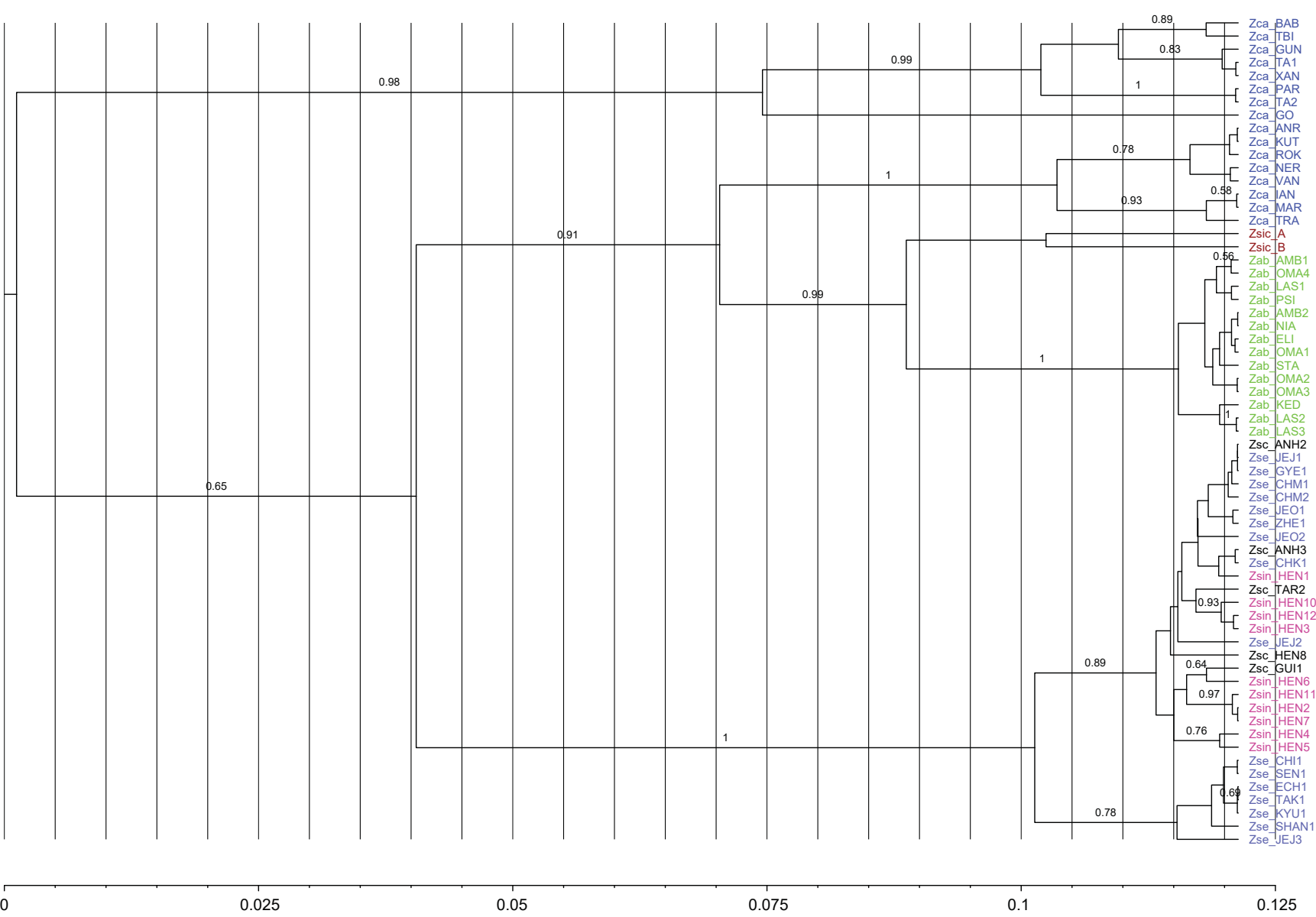

Fig. 3. (a) Chloroplast maximum credibility tree obtained with STACEY in BEAST2 for 285 Zelkova individuals belonging to 63 populations. Posterior probabilities higher than 0.5 are given above branches. (b) Similarity matrix giving the posterior probability that two populations belong to the same multi-species coalescent cluster (MSCC) according to the species tree in Fig. 3a. Black and white squares correspond to a posterior probability of 1 and 0 , respectively. Populations are given in the same order as in Fig. 3a. Zca: Z. carpinifolia; Zsic: Z. sicula; Zab: Z. abelicea; Zsin: Z. sinica; Zsc: Z. schneideriana; Zse: Z. serrata. 


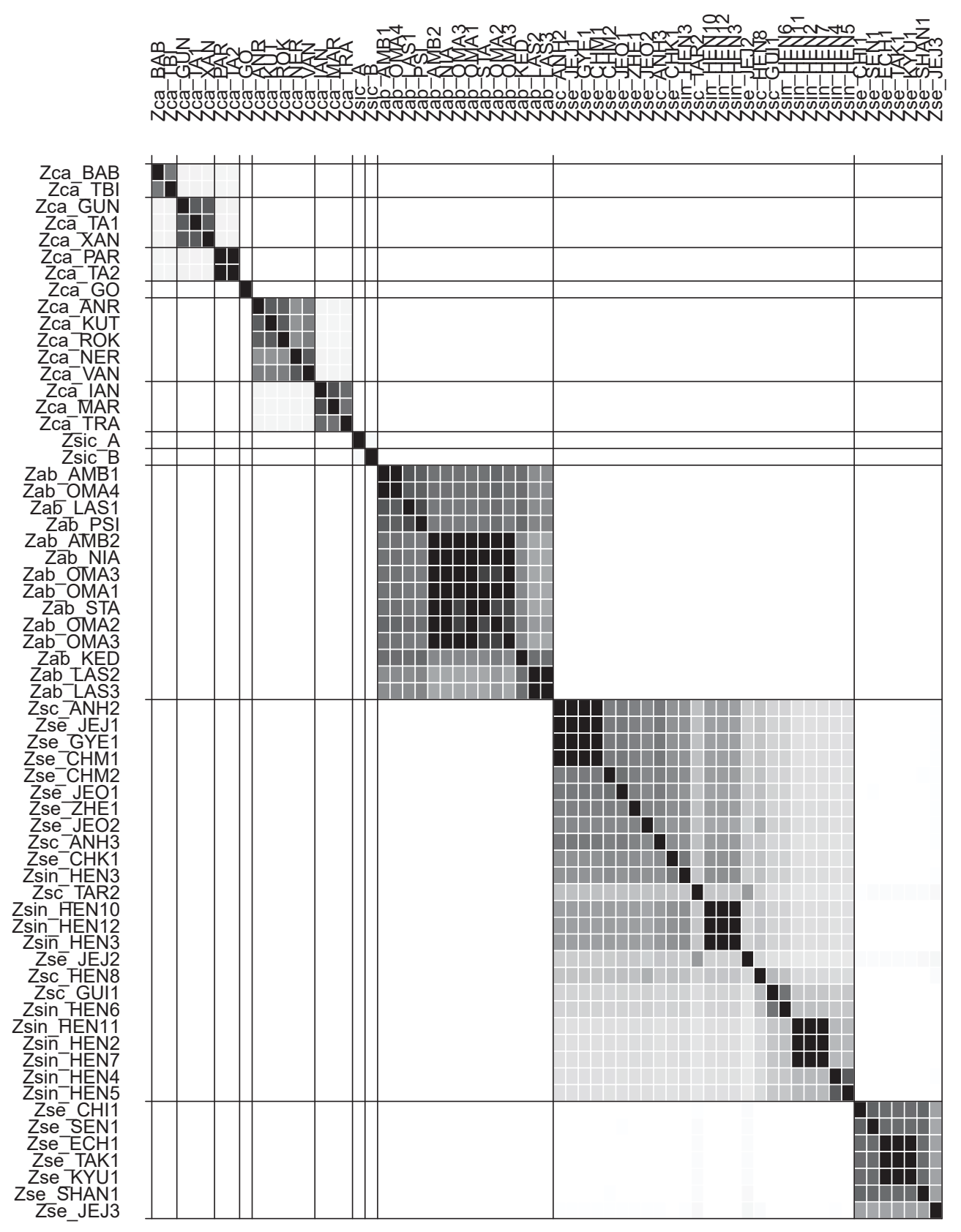

Fig. 3. (continued)

lineage comprises all other individuals of $Z$. serrata, $Z$. sinica and $Z$. schneideriana from Korea, mainland China and Taiwan, as also shown by the species delimitation similarity matrix (Fig. 3b). Therefore, a clear differentiation of the three species cannot be seen in the plastid network (Figs. 2 and 3a). A pattern showing a lineage split between China-Korea-Japan (CKJ) versus central-southern China was also detected in another relict tree genus, Juglans (Juglandaceae), and the divergence time inferred using a nuclear gene (LEAFY) dated the most common recent ancestor (MCRA) to the mid-Miocene. However, in other studies, this pattern was dated more recently, e.g., Cinnamomum camphora (China/Taiwan versus Japan occurred 50,000-358,500 years ago; Kameyama et al. 2017), Euptelea (Eupteleaceae) dated to the midto-late Pliocene (Cao et al., 2016), and the dominant forest tree Quercus glauca (Fagaceae) dated to the late Miocene-Pliocene (Xu et al., 2015). The different time scales of lineage divergence patterns for CKJ vs. mainland China inferred in subtropical and temperate taxa suggest that a land mass connection between CKJ existed multiple times during the Neogene (Van der Geer et al., 2010; Cao et al., 2016). It is assumed that the habitats on these land mass connections might have allowed dispersal across them.

At the nuclear level, however, the clustering clearly groups all the $Z$. serrata individuals together, regardless of whether they are from Japan, Korea or China, and the two other species form a distinct group. This result might be due to ascertainment bias since the analyzed microsatellites were characterized in Z. serrata and used on nonfocal species. However, if such a bias exists, then it should also result in a higher number of null alleles and associated heterozygote deficiencies, a lower number of alleles and shorter alleles in $Z$. sinica and $Z$. schneideriana than in Z. serrata (Hutter et al., 1998; Li and Kimmel, 2013). $F_{I S}$ values were indeed higher on average in the latter two species ( 0.248 for both) than in $Z$. serrata $\left(F_{I S}=0.148\right)$, but the number of alleles was equivalent in Z. serrata and Z. schneideriana (6.24 for both versus 5.58 for $Z$. sinica), with the allelic richness being the highest in $Z$. schneideriana. Moreover, no difference in the average size of alleles was noticed among the three species. Therefore, if ascertainment bias existed, then it seems to have had a limited impact on genotyping. 

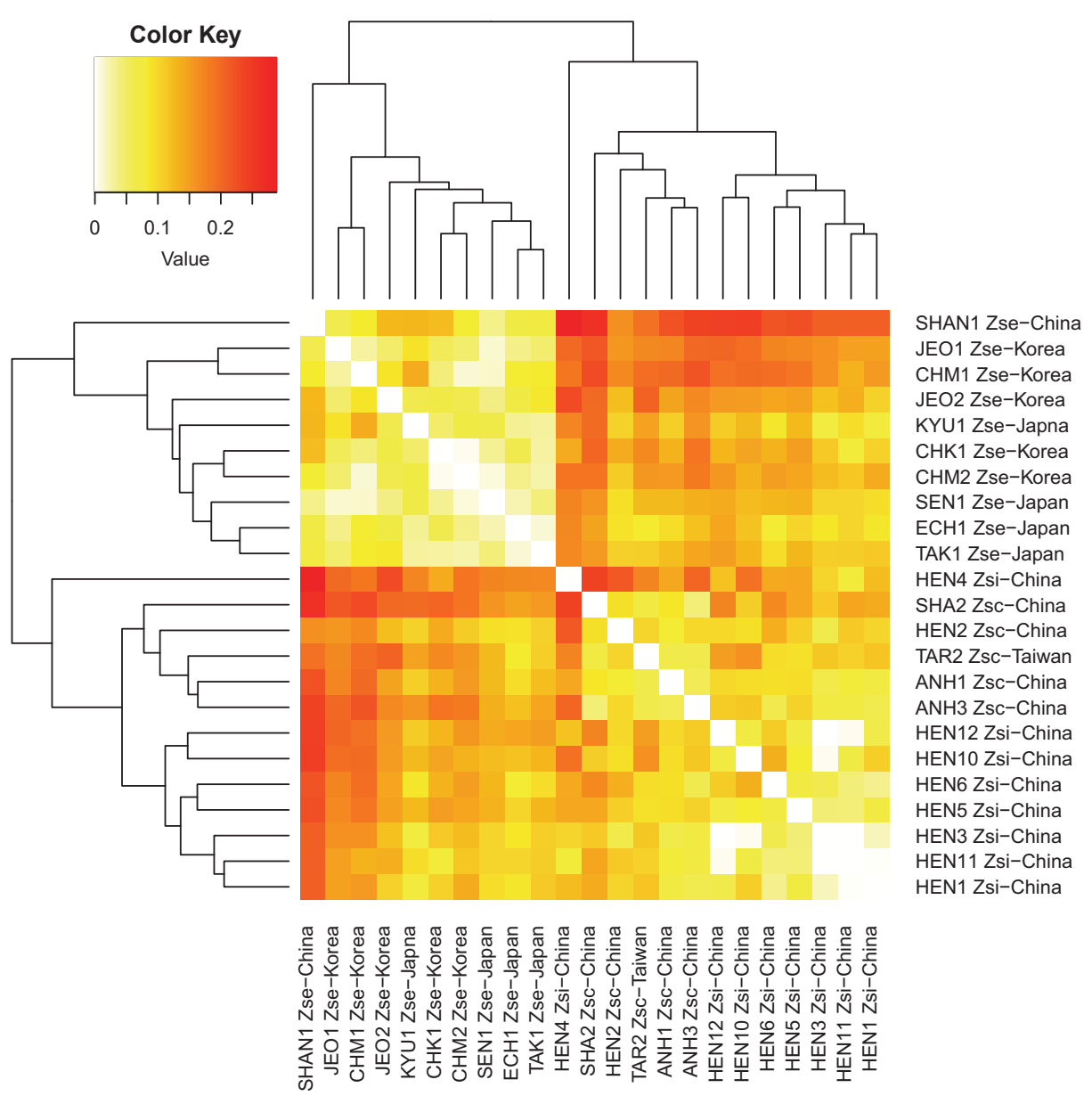

Fig. 4. $\mathrm{F}_{\mathrm{ST}}$ population heatmap and dendrogram based on pairwise $\mathrm{F}_{\mathrm{ST}}$ values between populations of the three East Asian species using 5 nuclear microsatellites.

a.

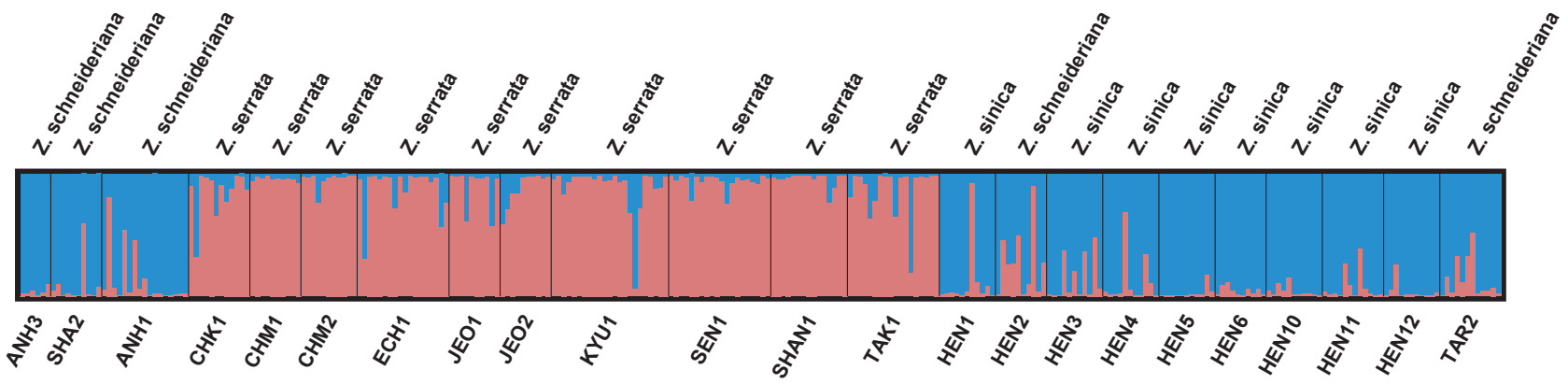

b.
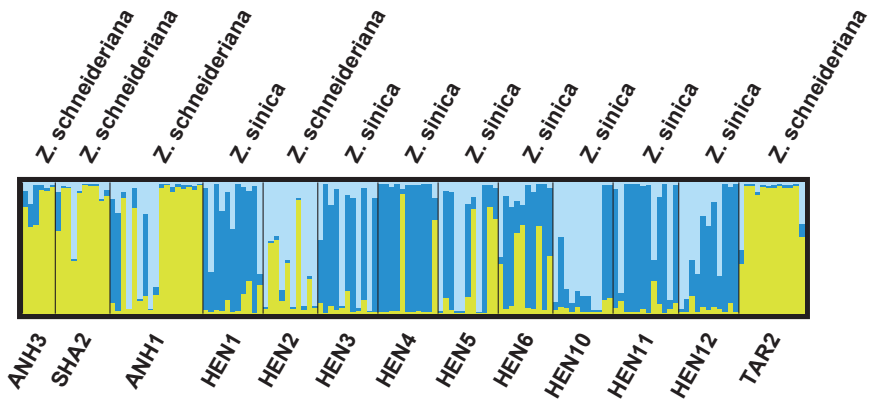

Fig. 5. Barplot from STRUCTURE analyses for 5 microsatellite markers. Each individual is represented by a vertical line divided by colored segments representing genetic clusters $(\mathrm{K})$ inferred in the Bayesian analysis. Species are given on top, and population names are given below. (a) Analysis for the three Asian species with $\mathrm{K}=2$, (b) Analysis for Z. schneideriana and Z. sinica individuals with $\mathrm{K}=3$. 
The most plausible scenario explaining the chloroplast and nuclear patterns described in our study is the survival of $Z$. serrata during the last ice ages in one of the putative refugia on the Korean Peninsula (e.g., Baek-in-san Mts refugium) and/or in southern Japan (e.g., Shikoku or Kyushu Island refugia), as defined in the compilation of the genetic imprints of the temperate flora by Qiu et al. (2011), and subsequent postglacial recolonization of China via land bridges. At the end of the last glacial period, the sea level dropped by ca. $85-140 \mathrm{~m}$, and the emerging land bridge was most likely covered by temperate deciduous forest linking southern Japan, the Korean Peninsula and China (MillienParra and Jaeger, 1999; Harrison et al., 2001). The two other East Asian Zelkova species (Z. sinica and Z. schneideriana) probably evolved in what is today southern China and occupied multiple local refugia during the last glacial periods, providing abundant opportunities for admixture and hybridization between them during the interglacial periods (explaining the weak genetic differentiation between these two species) and, to a lesser extent, for admixture with $Z$. serrata in the northeastern parts of their ranges.

Such survival in multiple refugia (mainly in high-altitude regions) and a complex mosaic genetic pattern due to interglacial recolonizations have been detected in numerous other relict species endemic to subtropical China, e.g., in Tetracentron sinense (Sun et al., 2014), Fagus lucida and F. longipetiolata (Zhang et al., 2013), Euptelea pleiosperma (Cao et al., 2016), Sargentodoxa cuneata (Tian et al., 2015) and Platycarya strobilacea (Wan et al., 2017).

Thus, the complex genetic pattern in East Asian Zelkova species detected in our study is most likely due to a combination of ancient allopatric speciation and more recent hybridization during the last glacial/interglacial retractions and recolonizations with at least partial overlaps in distribution ranges. Another explanation for haplotype sharing among the three species might be the persistence of ancestral polymorphism within species (also referred to as incomplete lineage sorting). Incomplete lineage sorting among species is known to be more important when speciation is recent within an abundant ancestral species, i.e., one with a large population effective size (Naciri and Linder, 2015). Accordingly, the diversification among the Asian species appears to have been quite recent in the species tree compared to that of the western species, particularly $Z$. carpinifolia. This result does not exclude the possibility of incomplete lineage sorting in species with lineages that can be traced back to 30 million years or more. Our scenario therefore allows for a better understanding of the very complex evolutionary and biogeographical history of relict trees in the SJFR.

\subsection{A contrasting story of genetic exchange: West versus east}

The three East Asian species, namely, Z. sinica, Z. schneideriana and $Z$. serrata, seem to have exchanged both chloroplast and nuclear genes and/or to have had high levels of incomplete lineage sorting. This finding is in striking contrast with what has been observed in the Transcaucasian and the Mediterranean refugia of $Z$. abelicea, $Z$. carpinifolia and Z. sicula (Christe et al., 2014b). As a consequence, the use of chloroplast loci for the three East Asian species does not allow the geographic origin of individuals to be traced back, as is the case for the western Eurasian species (Christe et al., 2014b). It is possible to trace the origin of plants only for Z. serrata to either Japan or outside Japan, considering that our sampling is rather dense for this species.

Gene exchange and/or incomplete lineage sorting in China is attested at the chloroplast level, as individuals of $Z$. schneideriana and $Z$. sinica share one haplotype (Z21) and Z. schneideriana and Z. serrata share another one (Z5E). Moreover, in the star-like part of the network, the haplotypes of the different species are quite intermingled, with those of $Z$. schneideriana usually located at the tips of the branches. One explanation could be that $Z$. schneideriana recurrently captured chloroplasts from $Z$. sinica or $Z$. serrata through hybridization and asymmetrical introgression. For this process to be possible and recurrent, large invading Z. schneideriana populations must have colonized places where the two other species were present, but at lower densities and numbers (Excoffier and Ray, 2008). Such an invasion could have taken place during the Quaternary and would have been possible because in China, the geographical barriers are mainly oriented northeast to southwest for the regions where the genus grows. Therefore, large areas where the different species could meet existed, and in opposition to the western Eurasian species, none of the species were trapped in small islands such as $Z$. sicula and $Z$. abelicea or restricted to isolated refuge areas such as Z. carpinifolia.

A second explanation could be that $Z$. schneideriana derives from one of the two other species (most likely $Z$. sinica) and that its features result from morphological convergence. This pattern would imply that $Z$. schneideriana is a more recent species, or at least a species that exhibits recent haplotypes. This last hypothesis is supported by the very low differentiation found between the two species at the nuclear level and in the haplotype network (Fig. 2).

\subsection{Zelkova schneideriana range extension to Taiwan?}

One of the surprising results of our study concerns the populations from Taiwan, which, genetically, are Z. schneideriana (nuclear and plastid data). Thus, their assignment to a separate taxon (Z. tarokoensis) or to Z. serrata as a variety (Z. serrata var. tarokoensis), as is today described in all local and national floras (Yang and Lu, 1996; Zheng-yi and Raven, 2003), should be revised. The reason for these assignments might be related to the history of the exploration of the Taiwanese flora. Taiwan was part of Japan between 1895 and the end of World Word II, and its flora was described one century ago by Japanese botanists who mainly knew Z. serrata from Japan. Another explanation is that the Taiwanese populations were initially populations of $Z$. serrata trapped in Taiwan that later underwent asymmetric backcrossing with the much closer Z. schneideriana, the dominant Zelkova species in southern China. The morphology would then still reflect a $Z$. serrata contribution, but with a full Z. schneideriana genetic background. Further fine-scale morphological and genetic studies are needed to test whether the Taiwanese individuals still deserve recognition as a discrete taxon.

Independent of the taxonomic question, the present results correspond much better to the biogeographic and geological history of Taiwan, with weak connectivity to Japan (via the Ryukyu Islands) and very strong past connectivity via land bridges with continental China, with the most recent having occurred during the Last Glacial Maximum (LGM; ca. 21 kya, Gao et al., 2015; Gong et al., 2016). Using pollen records, Liew et al. (1998) showed that Taiwan and China shared climate similarities during the LGM. Accordingly, similar patterns were observed for Quercus spinosa (Feng et al., 2017), Castanopsis eyrei (Shi et al., 2014) and Platycarya strobilacea (Wan et al., 2017), with Taiwanese populations being genetically similar to mainland populations. Kameyama et al. (2017) found that C. camphora was divided into two clusters, one comprising the Chinese and Taiwanese populations and a second comprising the Japanese populations. Gao et al. (2015), who worked on the Rosa sericea complex, which includes seven alpine species, described a cluster including populations from Taiwan and mainland China.

\subsection{A deep history}

It is commonly accepted that the genus Zelkova evolved ca. 55 million years ago (Mya) in the northern Pacific area, between what is today the USA and Japan (Burnham and Jeanette, 1986; Kozlowski and Gratzfeld, 2013). Haplotypes of Z. serrata from Japan seem to be more primitive and connect this taxon with the western Eurasian species in a median-joining network. This pattern is congruent with that recorded for Quercus and Fagus, for which the Japanese-Korean species are more closely related to their western Eurasian counterparts than to the geographically intermediate Chinese species (Denk and Grimm, 2005; Simeone et al., 2016; Renner et al., 2016). Our results, together with 
those of Denk and Grimm (2005) and Fukatsu et al. (2012), are consistent in finding that Z. serrata branches near Z. carpinifolia. Both species are genetically and morphologically more similar to the common ancestor of the modern Eurasian and East Asian taxa (see Denk and Grimm, 2005). Haplotypes of $Z$. abelicea and Z. sicula seem to have evolved more recently, and the same is true for $Z$. sinica and $Z$. schneideriana (Figs. 2,3a). The species tree suggests that plastid diversification in Z. carpinifolia started much earlier than that in all other species and that (at least some of) the within-species diversity has been maintained. Accepting a Paleocene-Eocene boundary origin of Zelkova, the two $Z$. carpinifolia plastid lineages would have emerged during the earliest (c. 20 Mya) and the latest portions of the Miocene (c. 8 Mya), the latter divergence occurring with the emergence of the East Asian clade (c. 9 Mya). Zelkova carpinifolia might even have diversified earlier since the relationship between the two former clades is not well supported. In contrast, all other species diversified quite recently, approximately 9 Mya for the clade comprising the three East-Asian species and after 5 Mya for $Z$. abelicea and the two Asian clades. The results show that $Z$. carpinifolia contains the most underived/ancient haplotypes in the west, whereas $Z$. serrata does so in the east. The modern western Eurasian and East Asian species did not evolve rapidly but instead are the result of stepwise diversification that is captured in markers from different genomes. Interestingly, Z. carpinifolia is highly structured at the chloroplast level (two well-supported clades), whereas Maharramova et al. (2015), using microsatellites, demonstrated that the species is weakly structured. This result thus confirms that the individuals belonging to the two chloroplast-based clades of $Z$. carpinifolia behave as members of a single species: plastid divergence and speciation are apparently decoupled in Zelkova, as also found for other extratropical trees such as Nothofagus (Premoli et al., 2012) and Quercus (Simeone et al., 2016). The existence of two chloroplast-based clades might be the result of very ancient structuring that lasted until the present due to relatively large effective population sizes. In contrast, all other Zelkova species seem to have diversified more recently. This finding does not imply that these other species are younger but instead that they might have experienced more genetic drift on average during their early history. This phenomenon is highly plausible for $Z$. sicula and $Z$. abelicea, which were both trapped on islands, but might also have been the case for the Asian species.

In conclusion, our data show footprints of both ancient and recent events of diversification with signs of past and ongoing admixture, more specifically between $Z$. sinica and $Z$. schneideriana. The numerous missing chloroplast haplotypes in the network however indicate that a large part of the past history has been erased. Further studies and more data from the nuclear genome, such as Gene Capture data (Lemmon et al., 2012), might help testing the hypotheses expressed above and give more accurate species delimitations for $Z$. sinica and $Z$. schneideriana.

\section{Acknowledgements}

We would like to warmly thank Dr. Guido Grimm for his invaluable comments and suggestions on a previous version of this manuscript. This work was supported by Fondation Franklinia. We are grateful to the Natural History Museum Fribourg and its director, Peter Wandeler. We would like to thank Pan Li from Zhejiang University, Hangzhou, China; Zhou Zhe-Kun and Yong-Jiang Huang from the Xishuangbanna Tropical Botanical Garden, Chinese Academy of Sciences, Kunming and Xishuangbanna, China; Naiqun Zhang from Nanyang Normal University, Henan, China; Zongcai Liu from Nanyang Normal College, Henan, China; Ralf Knapp Taipei, Taiwan; Kamata Naoto and Goto Susumu from the Graduate School of Agricultural and Life Sciences, Tokyo University, Japan; Suzuki Mitsuo and Kobayashi Kazutaka from the Botanical Garden of Tohoku University, Japan; Fujii Tomoyuki, Kazunori Takahashi and Okuda Shiro from the Forestry and Forest Products Research Institute, Kansai, Japan; Tatehiko Kamikawa from
Hatusima Arboretum, Kyushu, Japan; Chang Chin-Sung from Seoul National University, South Korea; Kim Hui from the College of Natural Science, Mokpo National University, South Korea; Woo-seok Kong from Kyung Hee University, Seoul, South Korea; and Chansoo Kim and Myungok Moon from the Korea Forest Research Institute, Jeju, South Korea, for their help in the field as well as Fadil Avdija, Luisa Carvalho and Régine Niba for their help with laboratory work. We are specially grateful to Simon Crameri who shared with us an improved version of the $\mathrm{R}$ script for species delimitation (https://github.com/scrameri/ smtools/tree/master/SpeciesDelimitation).

\section{Appendix A. Supplementary material}

Supplementary data to this article can be found online at https:// doi.org/10.1016/j.ympev.2019.02.010.

\section{References}

Arenas, M., Ray, N., Currat, M., Excoffier, L., 2012. Consequences of range contractions and range shifts on molecular diversity. Mol. Biol. Evol. 29, 207-218. https://doi. org $/ 10.1093 / \mathrm{molbev} / \mathrm{msr187.}$

Arthofer, W., Avtzis, D., Riegler, M., Stauffer, C., Stauffer, C., 2010. Mitochondrial phylogenies in the light of pseudogenes and Wolbachia: re-assessment of a bark beetle dataset. Zookeys 56, 269-280. https://doi.org/10.3897/zookeys.56.531.

Bandelt, H.-J., Forster, P., Röhl, A., 1999. Median-joining networks for inferring intraspecific phylogenies. Mol. Biol. Evol. 16, 37-48.

Barthlott, W., 2005. Global Centers of Vascular Plant Diversity and Holger KREFT (Bonn), Nov. Acta Leopoldina NF 92, 61-83.

Benjamini, Y., Yekutieli, D., 2001. The control of the false discovery rate in multiple testing under dependency. Ann. Stat. 29, 1165-1188. https://doi.org/10.1214/aos/ 1013699998.

Burnham, Jeanette, R., 1986. Foliar morphological analysis of the Ulmoideae (Ulmaceae) from the early Tertiary of Western North America. Palaeontogr. Abteilung B 135-167.

Cao, Y.-N., Comes, H.P., Sakaguchi, S., Chen, L.-Y., Qiu, Y.-X., 2016. Evolution of East Asia's Arcto-Tertiary relict Euptelea (Eupteleaceae) shaped by Late Neogene vicariance and Quaternary climate change. BMC Evol. Biol. 16, 66. https://doi.org/10. 1186/s12862-016-0636-X.

Christe, C., Caetano, S., Aeschimann, D., Kropf, M., Diadema, K., Naciri, Y., 2014a. The intraspecific genetic variability of siliceous and calcareous Gentiana species is shaped by contrasting demographic and re-colonization processes. Mol. Phylogenet. Evol. 70 323-336. https://doi.org/10.1016/j.ympev.2013.09.022.

Christe, C., Kozlowski, G., Frey, D., Bétrisey, S., Maharramova, E., Garfi, G., Pirintsos, S. Naciri, Y., 2014b. Footprints of past intensive diversification and structuring in the genus Zelkova (Ulmaceae) in south-western Eurasia. J. Biogeogr. 41, 1081-1093. https://doi.org/10.1111/jbi.12276.

Christe, C., Kozlowski, G., Frey, D., Fazan, L., Bétrisey, S., Pirintsos, S., Gratzfeld, J., Naciri, Y., 2014c. Do living ex situ collections capture the genetic variation of wild populations? A molecular analysis of two relict tree species, Zelkova abelica and Zelkova carpinifolia. Biodivers. Conserv. 23, 2945-2959. https://doi.org/10.1007/ s10531-014-0756-9.

Cornuet, J.M., Luikart, G., 1996. Description and power analysis of two tests for detecting recent population bottlenecks from allele frequency data. Genetics 144, 2001-2014.

Denk, T., Grimm, G.W., 2005. Phylogeny and biogeography of Zelkova (Ulmaceae sensu stricto) as inferred from leaf morphology, ITS sequence data and the fossil record. Bot. J. Linn. Soc. 147, 129-157. https://doi.org/10.1111/j.1095-8339.2005.00354.x.

Denk, T., Frotzler, N., Davitashvili, N., 2001. Vegetational patterns and distribution of relict taxa in humid temperate forests and wetlands of Georgia (Transcaucasia). Biol. J. Linn. Soc. 72, 287-332.

Di Rienzo, A., Peterson, A.C., Garza, J.C., Valdes, A.M., Slatkin, M., Freimer, N.B., 1994. Mutational processes of simple-sequence repeat loci in human populations. Proc. Natl. Acad. Sci. USA 91, 3166-3170.

Evanno, G., Regnaut, S., Goudet, J., 2005. Detecting the number of clusters of individuals using the software STRUCTURE: A simulation study. Mol. Ecol. 14, 2611-2620. https://doi.org/10.1111/j.1365-294X.2005.02553.x.

Excoffier, L., 2004. Patterns of DNA sequence diversity and genetic structure after a range expansion: lessons from the infinite-island model. Mol. Ecol. 13, 853-864. https:// doi.org/10.1046/j.1365-294X.2003.02004.x.

Excoffier, L., Foll, M., Petit, R.J., 2009. Genetic consequences of range expansions. Annu. Rev. Ecol. Evol. Syst. 40, 481-501. https://doi.org/10.1146/annurev.ecolsys.39. 110707.173414.

Excoffier, L., Laval, G., Schneider, S., 2007. Arlequin (version 3.0): an integrated software package for population genetics data analysis. Evol. Bioinform. Online 1, 47-50.

Excoffier, L., Ray, N., 2008. Surfing during population expansions promotes genetic revolutions and structuration. Trends Ecol. Evol. 23, 347-351. https://doi.org/10. 1016/j.tree.2008.04.004.

Excoffier, L., Smouse, P.E., Quattro, J.M., 1992. Analysis of molecular variance inferred from metric distances among DNA haplotypes: application to human mitochondrial DNA restriction data. Genetics 131, 479-491.

Fang, J., Wang, Z., Tang, Z. (Eds.), 2011. Atlas of Woody Plants in China. Springer Berlin 
Heidelberg, Berlin, Heidelberg https://doi.org/10.1007/978-3-642-15017-3.

Fang, Y., Liu, S., Xiang, J., Ge, J., 2007. Study on the natural population distribution of Zelkova schneideriana in Hubei. Resour. Environ. Yangtze Basin 16, 744

Feng, L., Zhang, Y.-P., Chen, X.-D., Yang, J., Zhou, T., Bai, G.-Q., Yang, J., Li, Z.-H., Peng, C.-I., Zhao, G.-F., 2017. Allopatric divergence, local adaptation, and multiple Quaternary refugia in a long-lived tree (Quercus spinosa) from subtropical China. bioRxiv 112375. 10.1101/112375.

Fukatsu, E., Isoda, K., Hirao, T., Takahashi, M., Watanabe, A., 2005. Development and characterization of simple sequence repeat DNA markers for Zelkova serrata. Mol. Ecol. Notes 5, 378-380. https://doi.org/10.1111/j.1471-8286.2005.00933.x.

Fukatsu, E., Watanabe, A., Nakada, R., Isoda, K., Hirao, T., Ubukata, M., Koyama, Y., Kodani, J., Saito, M., Miyamoto, N., Takahashi, M., 2012. Phylogeographical struc ture in Zelkova serrata in Japan and phylogeny in the genus Zelkova using the poly morphisms of chloroplast DNA. Conserv. Genet. 13, 1109-1118. https://doi.org/10. 1007/s10592-012-0358-6.

Gao, Y.-D., Zhang, Y., Gao, X.-F., Zhu, Z.-M., 2015. Pleistocene glaciations, demographic expansion and subsequent isolation promoted morphological heterogeneity: a phylogeographic study of the alpine Rosa sericea complex (Rosaceae). Sci. Rep. 5, 11698. https://doi.org/10.1038/srep11698.

Garfi, G., Carimi, F., Pasta, S., Rühl, J., Trigila, S., 2011. Additional insights on the ecology of the relic tree Zelkova sicula di Pasquale, Garfi et Quézel (Ulmaceae) afte the finding of a new population. Flora 206, 407-417. https://doi.org/10.1016/j. flora.2010.11.004.

Gong, W., Liu, W., Gu, L., Kaneko, S., Koch, M.A., Zhang, D., 2016. From glacial refugia to wide distribution range: demographic expansion of Loropetalum chinense

(Hamamelidaceae) in Chinese subtropical evergreen broadleaved forest. Org. Divers. Evol. 16, 23-38. https://doi.org/10.1007/s13127-015-0252-4.

Hall, T.A., 1999. BioEdit: a user-friendly biological sequence alignment editor and analysis program for Windows 95/98/NT. Nucleic Acids Symp. Ser. 41, 95-98. https:// doi.org/citeulike-article-id:691774.

Harrison, S.P., Yu, G., Takahara, H., Prentice, I.C., 2001. Palaeovegetation (Communications arising): Diversity of temperate plants in east Asia. Nature 413, 129-130. https://doi.org/10.1038/35093166.

Hayata, B., 1920. Zelkova tarokoensis. Icones Plant. formosanarum nec non Contrib. ad floram formosanam 9, 102-105.

Hutter, C.M., Schug, M.D., Aquadro, C.F., 1998. Microsatellite variation in Drosophila melanogaster and Drosophila simulans: a reciprocal test of the ascertainment bias hypothesis. Mol. Biol. Evol. 15, 1620-1636. https://doi.org/10.1093/oxfordjournals. molbev.a025890.

Ingvarsson, P.K., Ribstein, S., Taylor, D.R., 2003. Molecular evolution of insertions and deletion in the chloroplast genome of Silene. Mol. Biol. Evol. 20, 1737-1740. https:// doi.org/10.1093/molbev/msg163.

Jones, G., 2017. Algorithmic improvements to species delimitation and phylogeny estimation under the multispecies coalescent. J. Math. Biol. 74, 447-467. https://doi. org/10.1007/s00285-016-1034-0.

Jones, G., Aydin, Z., Oxelman, B., 2015. DISSECT: an assignment-free Bayesian discovery method for species delimitation under the multispecies coalescent. Bioinformatics 31 991-998. https://doi.org/10.1093/bioinformatics/btu770.

Kameyama, Y., Furumichi, J., Li, J., Tseng, Y.-H., 2017. Natural genetic differentiation and human-mediated gene flow: the spatiotemporal tendency observed in a longlived Cinnamomum camphora (Lauraceae) tree. Tree Genet. Genomes 13, 38. https:// doi.org/10.1007/s11295-017-1119-y.

Klopfstein, S., Currat, M., Excoffier, L., 2006. The fate of mutations surfing on the wave of a range expansion. Mol. Biol. Evol. 23, 482-490. https://doi.org/10.1093/molbev/ msj057.

Kozlowski, G., Frey, D., Fazan, L., Egli, B., Bétrisey, S., Gratzfeld, J., Garfi, G., Pirintsos, S., 2014. The Tertiary relict tree Zelkova abelicea (Ulmaceae): distribution, population structure and conservation status on Crete. Oryx 48, 80-87. https://doi.org/10.1017/ S0030605312001275

Kozlowski, G., Gratzfeld, J., 2013. Zelkova - an ancient tree. Global status and conservation action, Natural History Museum Fribourg, Switzerland.

Kozlowski, G., Bétrisey, S., Song, Y., Fazan, L., Garfi, G., 2018. The Red List of Zelkova. Natural History Museum Fribourg, Switzerland.

Kvavadze, E.V., Connor, S.E., 2005. Zelkova carpinifolia (Pallas) K. Koch in Holocene sediments of Georgia - an indicator of climatic optima. Rev. Palaeobot. Palynol. 133, 69-89. https://doi.org/10.1016/j.revpalbo.2004.09.002.

Lemmon, A.R., Enne, S.A., Lemmon, E.M., 2012. Anchored hybrid enrichment for massively high-throughput phylogenomics. Syst. Biol. 61, 727-744.

Li, B., Kimmel, M., 2013. Factors influencing ascertainment bias of microsatellite allele sizes: impact on estimates of mutation rates. Genetics 195, 563-572. https://doi.org/ 10.1534/genetics.113.154161.

Li, H.L., 1952. Zelkova serrata var, tarokoensis. J. Washingt. Acad. Sci. 42, 41.

Liew, P.M., Kuo, C.M., Huang, S.Y., Tseng, M.H., 1998. Vegetation change and terrestrial carbon storage in eastern Asia during the Last Glacial Maximum as indicated by a new pollen record from central Taiwan. Glob. Planet. Change 16-17, 85-94. https:// doi.org/10.1016/S0921-8181(98)00014-9.

Lu, L.M., Mao, L.F., Yang, T., Ye, J.F., Liu, B., Li, H.L., Sun, M., Miller, J.T., Mathews, S, Hu, H.H., Niu, Y.T., Peng, D.X., Chen, Y.H., Smith, S.A., Chen, M., Xiang, K.L., Le, C.T., Dang, V.C., Lu, A.M., Soltis, P.S., Soltis, D.E., Li, J.H., Chen, Z.D., 2018. Evolutionary history of the angiosperm flora of China. Nature 554, 234-238. https:// doi.org/10.1038/nature25485.

Maharramova, E.H., Safarov, H.M., Kozlowski, G., Borsch, T., Muller, L.A., 2015. Analysi of nuclear microsatellites reveals limited differentiation between Colchic and
Hyrcanian populations of the wind-pollinated relict tree Zelkova carpinifolia (Ulmaceae). Am. J. Bot. 102, 119-128. https://doi.org/10.3732/ajb.1400370.

Médail, F., Quézel, P., 2003. Conséquences écologiques possibles des changements climatiques sur la flore et la végétation du bassin méditerranéen. Bocconea 16, 397-422.

Millien-Parra, V., Jaeger, J.-J., 1999. Island biogeography of the Japanese terrestrial mammal assemblages: an example of a relict fauna. J. Biogeogr. 26, 959-972. https://doi.org/10.1046/j.1365-2699.1999.00346.x.

Milne, R.I., 2006. Northern hemisphere plant disjunctions: a window on tertiary land bridges and climate change? Ann. Bot. 98, 465-472. https://doi.org/10.1093/aob/ mcl148.

Milne, R.I., Abbott, R.J., 2002. The origin and evolution of tertiary relict floras. Adv. Botan. Res. https://doi.org/10.1016/S0065-2296(02)38033-9.

Naciri, Y., Linder, H.P., 2015. Species delimitation and relationships: the dance of the seven veils. Taxon 64, 3-16. https://doi.org/10.12705/641.24.

Naciri, Y., Manen, J.F., 2010. Potential DNA transfer from the chloroplast to the nucleus in Eryngium alpinum. Mol. Ecol. Resour. 10, 728-731. https://doi.org/10.1111/j. 1755-0998.2009.02816.x.

Nei, M., 1987. Molecular Evolutionary Genetics. Columbia University Press.

Posada, D., Crandall, K.A., 2001. Intraspecific gene genealogies: trees grafting into networks. Trends Ecol. Evol. 16, 37-45. https://doi.org/10.1016/S0169-5347(00) 02026-7.

Premoli, A.C., Mathiasen, P., Cristina Acosta, M., Ramos, V.A., 2012. Phylogeographically concordant chloroplast DNA divergence in sympatric Nothofagus s.s. How deep can it be? New Phytol. 193, 261-275. https://doi.org/10.1111/j.1469-8137.2011.03861.x.

Pritchard, J.K., Stephens, M., Donnelly, P., 2000. Inference of population structure using multilocus genotype data. Genetics 155, 945-959. https://doi.org/10.1111/j.14718286.2007.01758.X

Qiu, Y.-X., Fu, C.-X., Comes, H.P., 2011. Plant molecular phylogeography in China and adjacent regions: tracing the genetic imprints of Quaternary climate and environmental change in the world's most diverse temperate flora. Mol. Phylogenet. Evol. 59, 225-244. https://doi.org/10.1016/J.YMPEV.2011.01.012.

Rendell, S., Ennos, R.A., 2003. Chloroplast DNA diversity of the dioecious European tree Ilex aquifolium L. (English holly). Mol. Ecol. 12, 2681-2688.

Renner, S.S., Grimm, G.W., Kapli, P., Denk, T., 2016. Species relationships and divergence times in beeches: new insights from the inclusion of 53 young and old fossils in a birth-death clock model. Philos. Trans. R. Soc. B Biol. Sci. 371, 20150135. https:// doi.org/10.1098/rstb.2015.0135.

Ricklefs, R.E., Qian, H., 2000. Large-scale processes and the Asian bias in species diversity of temperateplants. Nature 407, 180-182. https://doi.org/10.1038/35025052.

Rousset, F., 2008. GENEPOP'007: a complete re-implementation of the GENEPOP software for Windows and Linux. Mol. Ecol. Resour. 8, 103-106. https://doi.org/10. $1111 / j .1471-8286.2007 .01931 . x$

Shaw, J., Lickey, E., Beck, J., Farmer, S., Liu, W., Miller, J., Siripun, K., Winder, C., Schilling, E., Small, R., 2005. The turtoise and the hare II : relative utility of 21 noncoding chloroplast DNA sequences for phylogenetic analysis. Am. J. Bot. 921, $142-166$.

Shi, M.-M., Michalski, S.G., Welk, E., Chen, X.-Y., Durka, W., 2014. Phylogeography of a widespread Asian subtropical tree: genetic east-west differentiation and climate envelope modelling suggest multiple glacial refugia. J. Biogeogr. 41, 1710-1720. https://doi.org/10.1111/jbi.12322.

Simeone, M.C., Grimm, G.W., Papini, A., Vessella, F., Cardoni, S., Tordoni, E., Piredda, R., Franc, A., Denk, T., 2016. Plastome data reveal multiple geographic origins of Quercus Group Ilex. PeerJ 4, e1897. https://doi.org/10.7717/peerj.1897.

Simmons, M.P., Ochoterena, H., 2000. Gaps as characters in sequence-based phylogenetic analyses. Syst. Biol. 49, 369-381.

Sun, Y., Moore, M.J., Yue, L., Feng, T., Chu, H., Chen, S., Ji, Y., Wang, H., Li, J., 2014 Chloroplast phylogeography of the East Asian Arcto-Tertiary relict Tetracentron sinense (Trochodendraceae). J. Biogeogr. 41, 1721-1732. https://doi.org/10.1111/jbi. 12323.

Taberlet, P., Gielly, L., Pautou, G., Bouvet, J., 1991. Universal primers for amplification of three non-coding regions of chloroplast DNA. Plant Mol. Biol. 17, 1105-1109. https://doi.org/10.1007/BF00037152.

Tian, B., Liu, T.L., Liu, J.Q., 2010. Ostryopsis intermedia, a new species of Betulaceae from Yunnan, China. Bot. Stud. 51, 257-262

Tian, S., Lei, S.-Q., Hu, W., Deng, L.-L., Li, B., Meng, Q.-L., Soltis, D.E., Soltis, P.S., Fan, D.M., Zhang, Z.-Y., 2015. Repeated range expansions and inter-/postglacial recolonization routes of Sargentodoxa cuneata (Oliv.) Rehd. et Wils. (Lardizabalaceae) in subtropical China revealed by chloroplast phylogeography. Mol. Phylogenet. Evol. 85, 238-246. https://doi.org/10.1016/j.ympev.2015.02.016.

Van der Geer, A., Lyras, G., De Vos, J., Dermitzakis, M., 2010. Evolution of Island Mammals. Adaptation and extinction of placental mammals on islands, WileyBlackwell, Chichester, West Sussex, UK.

Wan, Q., Zheng, Z., Huang, K., Guichoux, E., Petit, R.J., 2017. Genetic divergence within the monotypic tree genus Platycarya (Juglandaceae) and its implications for species' past dynamics in subtropical China. Tree Genet. Genomes 13, 73. https://doi.org/10. 1007/s11295-017-1153-9.

Whitlock, B.A., Hale, A.M., Groff, P.A., 2010. Intraspecific Inversions Pose a Challenge for the trnH-psbA Plant DNA Barcode. PLoS One 5, e11533. https://doi.org/10.1371/ journal.pone.0011533.

Xu, J., Deng, M., Jiang, X.-L., Westwood, M., Song, Y.-G., Turkington, R., 2015. Phylogeography of Quercus glauca (Fagaceae), a dominant tree of East Asian subtropical evergreen forests, based on three chloroplast DNA interspace sequences. Tree 
Genet. Genomes 11, 805. https://doi.org/10.1007/s11295-014-0805-2.

Yang, Y.-P., Lu, S.-Y., 1996. Flora of Taiwan. Second ed.

Yang, Z., Rannala, B., 2010. Bayesian species delimitation using multilocus sequence data. Proc. Natl. Acad. Sci. U. S. A. 107, 9264-9269. https://doi.org/10.1073/pnas 0913022107.

Zhang, M.-L., Wang, L., Lei, Y., Sanderson, S.C., 2017. Cenozoic evolutionary history of Zelkova (Ulmaceae), evidenced from ITS, trnL-trnF, psbA-trnH, and rbcL. Tree Genet. Genomes 13, 101. https://doi.org/10.1007/s11295-017-1182-4.

Zhang, Z.-Y., Wu, R., Wang, Q., Zhang, Z.-R., López-Pujol, J., Fan, D.-M., Li, D.-Z., 2013.
Comparative phylogeography of two sympatric beeches in subtropical China: Speciesspecific geographic mosaic of lineages. Ecol. Evol. 3, 4461. https://doi.org/10.1002/ ECE3.829.

Zheng-yi, W., Raven, P.H. (Ed.), 2003. Zelkova, in: Flora of China. Vol. 5 UlmaceaeBasellaceae. Missouri. Bot. Gard. Press, St. Louis.

Zidianakis, G., Iliopoulos, G., Fassoulas, C., 2010. A new late miocene plant assemblage from Messara basin (Crete, Greece). Bull. Geol. Soc. Greece Proc. 781-792. https:// doi.org/10.12681/bgsg.11244. 